Western University Scholarship@Western

Centre for Human Capital and Productivity. CHCP

Working Papers

Economics Working Papers Archive

2005

\title{
2005-3 Race, Poverty, and Teacher Mobility
}

Benjamin Scafidi

David L. Sjoquist

Todd R. Stinebrickner

Follow this and additional works at: https://ir.lib.uwo.ca/economicscibc

Part of the Economics Commons

Citation of this paper:

Scafidi, Benjamin, David L. Sjoquist, Todd R. Stinebrickner. "Race, Poverty, and Teacher Mobility." CIBC Centre for Human Capital and Productivity. CIBC Working Papers, 2005-3. London, ON: Department of Economics, University of Western Ontario (2005). 


\title{
Race, Poverty, and Teacher Mobility \\ by
}

Benjamin Scafidi, David L. Sjoquist and

Todd R. Stinebrickner

Working Paper \# 2005-3

February 2005

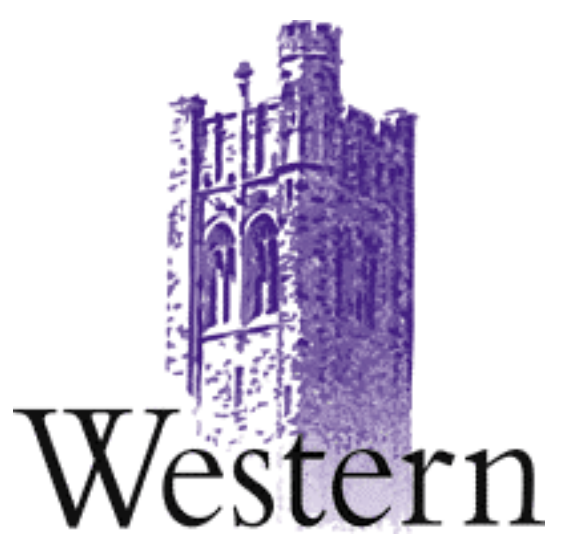

\section{CIBC Working Paper Series}

\author{
Department of Economics \\ Social Science Centre \\ The University of Western Ontario \\ London, Ontario, N6A 5C2 \\ Canada
}

This working paper is available as a downloadable pdf file on our website http://economics.uwo.ca/centres/cibc/ 


\title{
Race, Poverty, and Teacher Mobility
}

\author{
Benjamin Scafidi* \\ David L. Sjoquist* \\ Todd R. Stinebrickner** \\ *Georgia State University \\ ***University of Western Ontario
}

February 2005

Please direct correspondence to:

Todd R. Stinebrickner

Dept. of Economics

Social Science Centre

The University of Western Ontario

London, Ontario Canada

N6A 5C2

Email: trstineb@uwo.ca

Phone: 519 661-2111 ext. 85293

JEL: I2 Education.

Keywords: teacher turnover, teacher mobility, school characteristics, minority students, working conditions 


\begin{abstract}
This paper provides new information about the interrelated issues of teacher turnover (both within and across school districts and inside and outside of teaching) and the importance of nonpecuniary school characteristics, such as race and poverty, using new administrative data on Georgia teachers and the elementary schools in which they teach. Simple descriptive statistics indicate that teachers are more likely to change schools if they begin their teaching careers in schools with lower student test scores, schools with lower income students, or schools that have higher proportions of minority students. A linear probability and a competing risks model of transitions out of first teaching jobs allow us to separate the importance of these highly correlated school characteristics. The estimates from the model imply that teachers are much more likely to exit schools with large proportions of minority students, and that the other univariate statistical relationships associated with student test scores and poverty rates are driven to a large extent by the correlations of these variables with the minority variable. Thus we find that, while the common notion that teachers are more likely to leave high poverty schools is correct, it occurs because teachers are more likely to leave a particular type of poor school - that which has a large proportion of minority students.
\end{abstract}




\section{Introduction}

Most prior research related to the decisions of teachers has focused on the binary outcome of whether an individual decides to leave the teaching occupation. The motivation for such research was often a concern about the supply of teachers, and much attention was paid to the relationship between earnings and teacher attrition. However, teachers who remain in teaching do make decisions that are important for policy. For example, given recent evidence about the importance of teachers, the high levels of sorting of student groups across schools, and the concern with the educational opportunities of students from disadvantaged backgrounds, obtaining a better understanding of the factors associated with movements of inexperienced teachers between schools is an important research topic. ${ }^{1}$

This paper provides new information about the interrelated issues of teacher turnover/mobility and the importance of non-pecuniary school characteristics, such as race and poverty, using administrative data on Georgia teachers and on the elementary schools in which they teach. Our particular interest is in documenting how attrition patterns vary across types of schools. As such, we examine exits from individual schools (i.e. both teaching job changes within and across school districts as well as various types of exits out of teaching).

\footnotetext{
${ }^{1}$ The importance of teachers, and in particular inexperienced teachers, in explaining differential educational outcomes has been demonstrated in several studies (Ferguson 1991; Ferguson and Ladd 1996; Rivkin et al. 1998; Sanders, Saxton, and Horn 1997; Sanders and Horn 1998; Clotfelter, Ladd and Vigdor 2003).

There is a large degree of racial segregation in public elementary schools in Georgia. The index of dissimilarity for black and white students in Georgia public schools was 62.1 in the 2000-01 school year (Freeman, et al., 2002). This index number implies that 62.1 percent of Georgia public elementary school students would have to change schools in order for there to be an equal racial makeup in all Georgia public schools. Freeman, et al. also report high degrees of segregation by income class as well. Metropolitan areas in the Northeast and Midwest tend to have the most racially segregated schools (Clotfelter, 1999).
} 
To understand the relationship between non-pecuniary characteristics of schools and teacher decisions, examining exits from individual schools is important because we find that approximately 63 percent of all teaching changes take place within a district. Further, substantial variation in nonpecuniary school characteristics exist among schools within districts; in 1995, eighty percent of the variation in $3^{\text {rd }}$ grade test scores in the state of Georgia came from within-district variation, 41.3 percent of the variation in the proportion of students in a school who are black came from withindistrict variation, and 64.6 percent of the variation in the proportion of students in a school who are in poverty came from within-district variation.

Further, when mobility is modelled at a district level it becomes difficult in empirical work to know what current school characteristics to "attach" to a person who is considering a district change if substantial variation in school characteristics exists within districts and mobility within districts is common. For example, for a teacher who is currently working in a school with the most desirable characteristics in a district, it seems likely that the characteristics that are relevant when considering a district change are the characteristics in her particular school (since these are likely to be the characteristics that she will continue to have if she stays in the district). However, a teacher who is working in a school with the least desirable characteristics in the district is not likely to base the decision of whether to leave the district entirely on the characteristics at her current school if she thinks that, in the future, she may be able to move to a school in the district which has more desirable characteristics. In this case, deciding what characteristics are relevant for the decision is difficult from a practical standpoint. This particular measurement difficulty is avoided when mobility is modelled at the school level. Other recent research that examines movements out of particular 
schools includes Lankford et al. (2002) and Hanushek et al. (2004), which use data from New York State and Texas respectively. ${ }^{2}$

After describing our data in Section II, our empirical investigation in Section III begins by examining the types of univariate tabulations that also appear in the papers by Lankford et al. (2002) and Hanushek et al. (2004). We find that teachers are more likely to change schools-both within and across districts-if they begin their teaching careers in schools with lower student test scores, schools with lower income students, or schools that have higher proportions of minority students.

A primary contribution of our work is the use of a linear probability model and a competing risks model that allow us to examine the relative importance of these highly correlated school characteristics in explaining exits out of first schools. ${ }^{3}$ We find that teachers are much more likely to exit schools with large proportions of minority students, and that the relationships found for student test scores and poverty rates in the univariate tabulations are being driven to a large extent by the fact that these variables are highly correlated with the proportion of minority students in a school. More specifically, the results from both our linear probability model and competing risks model indicate that a one standard deviation increase in the proportion of black students in a school increases the probability that a "median type" teacher will exit a particular school in a particular year by more than twenty percent, whereas one standard deviation changes in student test scores, poverty, or teacher pay lead to only small changes in the overall exit probability.

\footnotetext{
${ }^{2}$ In earlier work, Theobald (1990) and Mont and Rees (1996) estimated models that explain the decisions of teachers in Washington state and New York state, respectively, to leave their school districts. Both of these studies combined attrition from teaching and moves across districts and did not consider moves within districts. Theobald and Gritz (1996) and Gritz and Theobald (1996) estimated models that explain the relationship between personal and school characteristics and the decisions of teachers in Washington state to move to a different school district, to move into public school administration, or to exit the state public education system.

${ }^{3}$ In terms of approaches that are closest to that of this paper, Hanushek et al. (2004) use data on Texas elementary teachers and schools to estimate multinomial logit models of teacher transitions out of school districts and out of teaching. Their competing risks results do not examine moves within districts. We became aware that Hanushek et al. (2004) were also working on this topic after completing an earlier draft of this paper.
} 
Thus, our use of these models allows us to say something very specific about the common suggestion that teachers are more likely to leave high poverty schools. Our empirical work indicates that, while this suggestion is true, it occurs because teachers are more likely to leave a particular type of poor school - one that has a large proportion of minority students. More generally, the main policy point of our paper is that, if one is interested in understanding mobility and attrition, it is of utmost importance to understand what is happening at schools with high proportions of minority students. Section IV provides concluding remarks including a discussion of whether high attrition rates at minority schools are likely to be indicative of low quality education at these schools.

\section{Data}

To analyze the mobility and retention of new elementary school teachers, we merged three sources of data on all public elementary schools teachers and all public elementary schools in Georgia. ${ }^{4}$ Data on the characteristics of individual teachers from the 1991-92 school year to the 2000-01 school year were obtained from the administrative records kept by the Georgia Professional Standards Commission (GAPSC). Characteristics of individual elementary schools from 1994-95 to 2000-2001, including racial composition, average student achievement on standardized exams, and percentage of students eligible for free or reduced lunch were provided by the Georgia Department of

\footnotetext{
${ }^{4}$ Georgia is in many ways roughly an "average" state. Georgia's median household income in 1999 was about $\$ 39,500$, ranking $26^{\text {th }}$ in the U.S. Women working in Georgia earned $\$ 934$ more than the national median for women. Georgia students in the $3^{\text {rd }}, 5^{\text {th }}$, and $8^{\text {th }}$ grades scored very close to or at the national average on the battery of Stanford 9 exams administered in 2001 (Georgia Department of Education, 2002). Almost 83 percent of Georgia residents have at least a high school diploma, compared to 84 percent nationwide. According to the National Education Association, teacher salaries in Georgia are slightly below the national average, the highest in the southeast, and $17^{\text {th }}$ highest in the nation (Salzer, 2001). The rate of adults over age 25 with at least a college degree is lower in Georgia relative to the nation-23.1 percent in Georgia and 25.6 percent overall. Georgia differs from the rest of the nation with respect to homeownership and racial composition as well. In 1999, 71.3 percent of Georgians owned their homes compared to a rate of 66.8 percent nationally. Nationally, 30.9 percent of individuals are nonwhite or of mixed race, compared to 37.4 percent of Georgians. Unless otherwise noted, all information in this footnote comes from the U.S. Department of the Census web site, www.census.gov.
} 
Education (GADOE). Actual quarterly wages paid to the teachers and former teachers comes from administrative payroll records from the state unemployment insurance (UI) system maintained by the Georgia Department of Labor (GADOL). These data are referred to as ES202 data. ${ }^{5}$ Virtually all employees are subject to the UI tax, and thus virtually all wages in non-teaching occupations are observed. The ES202 data identify the industry (4-digit SIC code), but not the occupation of each individual. $^{6}$

Merging these three sources of data allows us to differentiate between the reasons that a teacher may leave his/her first teaching job. If an individual is no longer working as a full-time teacher, but receives wages from a public school district, we classify him/her as working in "other education sector employment.” If a former teacher does not have a wage in the ES202 file, then he/she is either living in Georgia but not working, living in another state and not working, living in another state and working as a teacher, or living in another state and working in a non-teaching occupation. The data do not allow us to differentiate between these possibilities so we group them together in a "leaving the Georgia workforce" category. Note that we also classify individuals who

\footnotetext{
${ }^{5}$ The ES202 data are described in detail by White and Geddes. (1990). All employers covered in the unemployment insurance system report each employee's wages to the GADOL on a quarterly basis. The ES202 data identify the industry (4-digit SIC code), but not the occupation of each individual. Using ES202, the actual wages paid to teachers and former teachers were matched with the teacher records in the GAPSC files by social security number. For individuals listed in the GAPSC files as teachers for a given year, the match of wages to teachers was almost perfect-of the roughly 820,000 teacher records over the 10-year period, only 7 records could not be matched to wage information in the ES202 data files.

${ }^{6}$ Each record in the GAPSC data contains a job code, which is used to determine which individuals are teaching. Nevertheless, a large number of these teachers have low actual wages as reported by ES202. Perhaps these teachers were working for only part of the academic year. Since we do not know why these individuals are not earning a full-time annual teaching wage, we did not want to characterize their wage necessarily as their observed annual wage. Teaching wages are observed quarterly in the ES202 data: January-March, April-June, July-September, and October-December. Georgia teachers are paid on 12-month contracts. Since the quarterly data do not match the school year, care had to be taken in constructing annual teaching wages. In the $3^{\text {rd }}$ quarter of the calendar year, the ES202 data will contain wages for teachers from two different academic years. To avoid this issue and the issue of teachers leaving in the middle of an academic year, we took the highest quarterly teaching wage from the other three quarters and annualized that figure. Teachers making decisions on whether to leave the profession surely consider the wage they would be paid for the entire academic year as the wage offered in teaching. One drawback of using actual wage information is that some variation in wages is true differences in wages across districts, while some variation is due to differences in educational attainment. In our data, just over 90 percent of the sample of new teachers never earned more than a bachelor's degree during the same period. We also conducted our analyses with only these teachers and obtained very similar results to those reported in this paper.
} 
earn less than $\$ 10,000$ in annual wages as having left the Georgia workforce. Individuals who earn wages outside the Georgia public education sector are labelled as working in the "non-education sector." Finally, the data allow us to identify the particular school and school district in which the teacher is employed so we are able to differentiate between exits to a new school within the district and to a new school in another district.

We study the seven years between the 1994-95 academic year and the 2000-01 academic year. Our sample contains 11,070 elementary teachers who began teaching between 1994-95 and 1999-00 in Georgia and were under the age of 27 when they began their teaching career. ${ }^{7}$

Variable definitions and summary statistics of the characteristics of teachers and their schools are listed in Table 1. We report summary statistics from the first year of each first teaching job. As shown in Table 1, individuals on average work in schools in which 0.464 of students live in poverty (POVERTY), i.e. eligible for free or reduced price lunch, and 0.388 of students are black (PBLACK). The mean percentile rank on the Iowa Test of Basic Skills (TEST) at teachers' first schools is $53.28 .^{8}$ Our sample of new teachers is overwhelmingly female (87.5 percent), and only 16.7 percent of teachers identify themselves as non-Hispanic blacks (BLACK). ${ }^{9}$ Mean wages in the first year of teaching are approximately \$30,000, in constant year 2000 dollars.

Table 2 contains the number of teachers in each of the transition categories under study. For the six annual cohorts in the data, we observe a minimum of one, a maximum of 6 , and an average of 3.46 yearly decisions before the end of the sample period, which takes place in 2000-2001 school year. Defining a teaching job to be employment at a particular school, a teacher is defined to make a

\footnotetext{
${ }^{7}$ Limiting our sample to teachers aged 27 or younger, essentially ensures that our new teachers have not previously taught in Georgia. We cannot rule out the possibility that some of these teachers may have taught in other states before arriving in Georgia. However, the results in the paper are robust to reducing the cutoff age which removes teachers most likely to have taught elsewhere. Evidence in Rivkin et al. (1998) that teachers gain valuable experience during early years of teaching is one motivation for studying new teachers.

${ }^{8}$ For an individual elementary school, this test score is the mean of the $3^{\text {rd }}$ grade Reading and Math exams.
} 
transition when he/she leaves his/her first teaching job. Of the 11,070 new teachers in our sample, 4,222 (38 percent) remain at the same school through the end of the sample period, and thus have a censored spell. However, Table 2 indicates that a large proportion of new teachers end their first teaching spell by changing schools. During the sample period, 20.9 percent of all teachers end their first teaching job by moving to a new school in the same school district and 12.4 percent of all teachers end their first teaching job by moving to a teaching position in another school district.

To provide information about yearly transition rates, we aggregate over all person-years in the first teaching jobs of all individuals in our sample. We find that a person makes the decision to remain in his/her first school (i.e., does not leave his/her first teaching job) in 0.714 of these personyears. The yearly proportions associated with other transitions are as follows: accepting a new teaching job in the same school district (0.094); accepting a new teaching job in a different school district (0.052); accepting an administrative or other non-teaching job in the education sector (0.043); accepting a non-education sector job (0.016); and exiting the Georgia workforce entirely $(0.082) .{ }^{10}$

\section{The Role of School Characteristics in Teacher Mobility and Retention}

In this section, we analyze the role of school characteristics on teacher mobility and retention.

In Section III.1, we use univariate tabulations to examine whether school characteristics in first jobs are different for those who exit these first jobs and those that do not exit these first jobs. In Section III.2, we present results from a linear probability model and results from a competing risks model that allow us to examine the relative importance of school characteristics in explaining exits from

\footnotetext{
${ }^{9}$ We use PBLACK to represent the proportion of students in a school that are black and we use BLACK to indicate whether a particular teacher is black. The proportion of the sample that is not non-Hispanic black or white is very small-less than 2 percent.

${ }^{10}$ The small proportion associated with accepting a non-education job in Georgia is consistent with Stinebrickner (2001) and Stinebrickner (2002) who found that women who leave teaching often leave the workforce altogether for reasons related to marriage and fertility. An examination of what teachers do when they leave teaching is the focus of Scafidi et al. (2002).
} 
first teaching jobs. Finally in Section III.3, we show how school characteristics change for teachers who move between schools.

\section{III.1 Univariate Analysis of Teacher Turnover}

A teacher's decision to leave his/her first teaching job may depend on both wages and nonpecuniary characteristics of schools. ${ }^{11}$ In this subsection, we examine whether teachers who remain in their first teaching job have, on average, different school characteristics than those who leave their first teaching job for each of the possible exit activities that we described above and for all of the exit activities aggregated. Specifically, using all person-years in the first teaching jobs of all individuals in our sample, Table 3 shows the average school characteristics at time $t$ for those who remained in the first teaching job at time $t+1$ (column 1), those who accepted a new teaching job in the same school district at time $t+1$ (column 2), those who accepted a new teaching job in a different school district at time $t+1$ (column 3), those who accepted an administrative or other non-teaching job in the education sector at time $t+1$ (column 4), those who accepted a non-education sector job at time $t+1$ (column), those who exited the Georgia workforce entirely at time $t+1$ (column 6), and those who exited for any of the activities in columns 2-6 (column 7). ${ }^{12}$

\footnotetext{
${ }^{11}$ Mandated by state law and updated annually, Georgia public schools districts face a minimum salary schedule that lists the minimum teacher salary that must be paid based on teacher certification status, experience, and education. Variation in salary arises because local school districts may pay teachers a local supplement to the salary schedule, and many do so. The standard deviation of salary for new teachers with no more than a bachelor's degree in 199495 was about \$3,500. Unlike parts of the U.S., there is no collective bargaining between teacher unions and local school districts.

${ }^{12}$ The total number of years contributed by a particular person is the total number of years that he remained in his first teaching job. For example, if a person chose to remain in her first teaching job at the end of the first three years of teaching and then changed to a new teaching job in the same district after the fourth year, then the school characteristics in each of the first three years would contribute to the average associated with remaining in the first teaching job and the school characteristics in the fourth year would contribute to the average associated with changing to a new teaching job in the same district. An alternative descriptive approach that would produce substantially bigger differences in average school characteristics would be to have school characteristics contribute to the average associated with remaining in the first teaching job only if the person never leaves the first teaching job during the sample period. We choose our approach because it is most analogous to the empirical work in the remainder of the paper.
} 
With respect to changing teaching jobs, the first three entries in the first row of Table 3 show that wages of teachers at time $t$ do not differ substantially between teachers who remain at their first teaching job at time $t+1$ and teachers who change teaching jobs at time $t+1$. By contrast, the first three entries of the fourth row of Table 3 show that the racial composition of schools (PBLACK) at time $t$ does differ significantly between teachers who remain at their first teaching job at time $t+1$ and teachers who change teaching jobs at time $t+1$. Teachers who remain at their first school at time $t+1$ served a student population at time $t$ that was on average 0.372 black. Teachers who move to other schools within the same district at time $t+1$ served a student population at time $t$ that was on average 0.393 black, while teachers who change districts at time $t+1$ served a student population at time $t$ that was on average 0.466 black. A similar pattern exists for both the poverty status of students (POVERTY) and the achievement test score (TEST). Teachers who move to other schools at time $t+1$ taught in schools at time $t$ that had higher poverty rates and lower test scores than teachers who did not move to other schools, with larger differences for teachers who change school districts than for teachers who change schools within a district.

With respect to leaving teaching for other education jobs, Table 3 indicates that teachers who accept administrative or other non-teaching education jobs at time $t+1$ had lower wages and were in schools with lower test scores, higher poverty rates, and higher proportions of minority students at time $t$ than teachers who remain in their same teaching job at time $t+1$. With respect to leaving education jobs altogether, Table 3 indicates that teachers who leave teaching for a non-education sector job or leave the Georgia workforce altogether at time $t+1$ were, on average, in schools with higher proportions of black students at time $t$ than teachers who remain in their same teaching job at time $t+1$. By and large, there are no differences in the means of other school characteristics at time $t$ for those teachers who remain in their same teaching jobs at time $t+1$ and those who left teaching for non-education jobs or left the Georgia workforce entirely at time $t+1$. 
The last column of Table 3 shows the school characteristics aggregated over all of the exit activities in columns (2)-(6). The results show that teachers who leave teaching (for any of the exit activities) in time $t+1$ had significantly lower wages and were in schools with lower test scores, higher poverty rates, and higher proportions of minority students at time $t$ than teachers who remain in their same teaching job at time $t+1$. Tests of the null hypotheses that the means are the same for those who exit and those who do not exit are rejected at traditional levels for each of the four school characteristics at traditional values with t-statistics of $-2.34,-11.62,2.71$, and 9.040 for WAGE, TEST, POVERTY, and PBLACK respectively.

\section{III.2 A Linear Probability and Competing Risks Analysis of Teacher Mobility and Retention}

The analysis in the previous section indicates that teachers who leave their first schools for new teaching jobs were more likely to serve minority, disadvantaged, and lower achieving students in the year prior to exiting than teachers who did not leave their first teaching jobs and that this finding is driven to a large extent by those who left their first teaching jobs for other teaching jobs. These three non-pecuniary school characteristics are highly correlated. The correlation between PBLACK and POVERTY is 0.74. The correlation between PBLACK and TEST is -0.54 , and the correlation between POVERTY and TEST is -0.62. In contrast, teaching wages are not highly correlated with student test scores, student poverty rates, or student racial composition (the correlations are $0.09,-0.07$, and 0.04 , respectively).

The reality that these school characteristics are highly correlated combined with the policy significance of determining the relative importance of the various characteristics in explaining teacher exits motivates our estimation of two econometric models. We first estimate a linear probability model that does not distinguish between different possible exit activities. This model has the virtues of being easy to interpret and not relying on any functional form assumptions. We then 
estimate a competing risks model that provides information about the relationship between characteristics and each of the different possible exit activities that was examined in Table 3.

\section{$\underline{\text { A Linear Probability Model }}$}

Using all person-years in the first teaching jobs of all individuals in our sample, we estimate a linear probability model of the form:

$$
\text { Exit }_{i t}=\alpha X_{i t}+B(t)+u_{i t}
$$

The dependent variable Exit ${ }_{i t}$ is equal to one if a person leaves his first teaching job after year $\mathrm{t}$ for any of the activities in columns (2)-(6) of Table 3 and is equal to zero otherwise. $X_{i t}$ is the vector of observable personal and school characteristics of teacher $i$ at time $t$ and are described in Table 1. $B(t)$ is a function which determines the relationship between the dependent exit variable and the number of years, $t$, that a person has been in her first teaching spell. We assume a non-parametric form:

$$
B(t)=\delta_{1} I(t=1)+\delta_{2} I(t=2)+\delta_{3} I(t=3)+\ldots+\delta_{6} I(t=6)
$$

where $I$ is an indicator function that is equal to one if its argument is true. The number of terms in equation (2) comes from the fact that a maximum number of six decision years can be observed for teacher $i^{13} u_{i t}$ represents unobserved characteristics of teachers, school, and communities that influence the exit decision.

The results from this specification are shown in Table 4. Most striking in Table 4 are the results associated with the proportion of students in a school that are black, PBLACK. The point estimate, 0.188 , is both quantitatively and statistically large. With respect to the former, the point estimate taken together with the standard deviation of PBLACK from Table 1 implies that a one standard deviation increase in PBLACK raises the probability that a (non-black) teacher will leave his/her first teaching in a particular year by approximately 0.06 , or about twenty-one percent of the

\footnotetext{
${ }^{13}$ The first teaching year is 1994-95. The last year of our sample is 2000-01.
} 
annual exit rate from teaching (0.286) that was described at the end of Section II. With respect to the latter, a test of the null hypothesis that PBLACK has no effect on exits from first teaching jobs is overwhelmingly rejected with a t-statistic of more than twelve. ${ }^{14}$ The interaction of PBLACK with the indicator of whether a teacher is black (BLACK) indicates that black teachers are significantly less likely to leave minority schools than are white teachers.

Thus, the multivariate results for PBLACK are consistent with the difference-in-means test from the univariate tabulations described in the last paragraph of Section III.1 which produced a tstatistic of more than nine. Also similar in spirit to the univariate results from Table 3 is the estimate associated with the teaching wage. A test of the null hypothesis that LOGWAGE has no effect on mobility yields a t-statistic of -2.65 in Table 4 which is similar to the level of significance from the difference-in-means test described in the last paragraph of Section III.1 for the univariate tabulations. Not surprising given the difference in the level of significance between the PBLACK and the LOGWAGE variable, the latter is found to have a much smaller quantitative effect than the former with a one standard deviation increase in LOGWAGE decreasing the annual exit rate out of the first teaching job by less than 0.01 .

Unlike the findings for PBLACK and LOGWAGE, the results associated with TEST and POVERTY highlight the importance of the multivariate model. For example, with respect to the former variable, the difference-in-means test associated from the univariate tabulations produced a tstatistic of -11.62 in Table 3. However, the t-statistic associated with TEST falls to approximately -1.62 in Table 4. With respect to POVERTY, the difference-in-means test from Section III.1 suggested that higher poverty was related to higher mobility (with a t-statistic of 2.71), but the results in Table 4 indicate that this is not the case after conditioning on other school characteristics. In fact,

\footnotetext{
${ }^{14}$ We found little difference in our results when we estimated the model separately by sex. For example, the estimated effect (std. error) of PBLACK was $0.189(0.016)$ when the model was estimated separately for women and was $0.172(0.044)$ when the model was estimated separately for men.
} 
the results in Table 4 indicate that, after controlling for the other variables, higher poverty is related to lower mobility.

Intuitively, the difference between the univariate and multivariate results for the TEST and POVERTY variables arises primarily because these variables are strongly correlated with the PBLACK variable, which plays a very important role in the mobility decision and with each other. To confirm that this is the case, we estimated two additional specifications. In one alternative specification we excluded the POVERTY and PBLACK variables and found that the estimated coefficient on TEST was -0.002 with a t-statistic of -8.05 that is much more consistent with what was found in the univariate analysis. In a second alternative specification we excluded the TEST and PBLACK variables and found that, consistent with the univariate results, the point estimate associated with POVERTY indicates that higher poverty is related to significantly higher mobility. As expected, we also found that removing the TEST and POVERTY variables had virtually no effect on the estimated effect of PBLACK.

Credibly estimating the causal impact of school characteristics in our data and also in the data used by others in the teacher mobility/attrition literature is extremely difficult. One reason that $u_{i t}$ in equation (1) may be correlated with observed school characteristics is that observed school characteristics may be related to other important characteristics of schools that are unobserved. Another reason that $\mathrm{u}_{\mathrm{it}}$ may be correlated with observed school characteristics is that variation in school characteristics across teachers is generated by the decisions of teachers and districts and these decisions depend, at least in part, on unobserved preferences and quality of teachers. As such, in our opinion, our results and the results in each of the other studies in this literature are best viewed as being primarily "descriptive” in nature with a primary capability of providing policymakers with 
information about what types of schools have the highest turnover rates. ${ }^{15,}{ }^{16}$ In this vein, we believe that this paper makes an important contribution by providing new information about specific perceptions that are common in policy discussion. As one prominent example, driven largely by a belief that high attrition rates at schools are indicative of lower quality education, there has been substantial reference to a perception that teachers are much more likely to leave high poverty schools. Our results indicate that, while this perception is correct, it occurs because teachers are more likely to leave a particular type of poor school - one that has a large proportion of minority students. More generally, the main policy point from the linear probability model is very direct - if a policymaker is interested in understanding retention and attrition issues, then it is of importance to gain a better understanding of what is happening at schools with high minority rates. ${ }^{17}$

As mentioned earlier, the other work that is most similar to our approach is Hanushek et al. (2004) who primarily examine exits out of school districts rather than exits out of particular schools. Most comparable to our results in Table 4 are the Hanushek et al. (2004) results for a linear probability model that examines exits for teachers who are in their first three years of teaching. ${ }^{18}$ Consistent with our results, the percentage of students that are black is the most important of the

\footnotetext{
${ }^{15}$ This is not to suggest that understanding the causal impact of characteristics is not of importance. Indeed, it is our opinion that future work that could explore issues related to causality and correlation in this context would be extremely valuable.

${ }^{16}$ Given our interest in providing information about this particular descriptive relationship, we did not pursue certain other specifications such as those that include school district Fixed Effects (FE). In many contexts, it has been suggested that FE specifications are useful for getting "closer" than OLS to a causal relationship. However, in this context, it is certainly not clear that this would be the case. Indeed, if teachers tend to work in school districts where they lived when young, then the across-district variation in school characteristics (that is removed by FE) may be less susceptible to endogeneity problems than the within-district variation (that is used by the FE estimator for identification) since the latter is generated by decisions of teachers and school districts during the initial school matching process. While the relationship identified by a FE specification could certainly be interpreted in a descriptive manner, it is not the descriptive relationship that we are primarily interested in.

${ }^{17}$ We also examined modifications to our specification that might help provide additional information about what types of schools teachers are most likely to leave. For example, in order to examine whether the high rate of exits from minority schools is related to the fact that these schools are more likely to be in cities, we estimated a model that included an urban indicator variable. We found that this inclusion had very little effect on the estimated effect of PBLACK with the t-statistic (coefficient) on PBLACK found to be 0.184 (11.648). The general message that the minority status of a school is extremely important and that other characteristics play a much smaller role was found to be very robust across additional specifications that included additional information (e.g., unemployment rates) about the communities in which individuals live.
} 
variables in their regression both statistically and economically (with a t-statistic of over seven and a point estimate of approximately two-thirds of what we find). Also consistent with our results, they find that, conditional on other variables of the type we have also included, schools with higher percentages of students that are eligible for free and reduced lunch do not have higher attrition rates and that a student test score variable is statistically significant but at a much lower level of significance than the black variable. ${ }^{19}$ In short, the general message from their paper and this one is strikingly similar.

\section{$\underline{\text { A Competing Risks Model }}$}

In this subsection, we analyse the impact of salary and school characteristics on each of the various transitions made by teachers. Unlike the linear probability model used in the previous subsection, the competing risks hazard model used here makes distinctions between various possible reasons that a person may leave his/her first teaching job. Specifically, the model distinguishes between remaining in the same school $(F)$ and exiting to a teaching job in another school within the same district $(W)$, exiting to a teaching job in another district $(D)$, exiting to a non-teaching job (other than full-time teaching) within the Georgia public education system $(E)$, exiting to another job outside the Georgia public education system $(N)$, and exiting out of the Georgia workforce altogether $(O) .{ }^{20}$ While the empirical model described in the previous subsection is useful for analyzing overall teacher turnover, it is useful to know something about the relationship between salary, school characteristics, and these individual transitions.

\footnotetext{
${ }^{18}$ See the first column of Table 7 in Hanushek et al. (2004).

${ }^{19}$ When the linear model is estimated using teachers with 3-5 years of experience Hanushek et al. (2004) find a significant effect of POVERTY, but as in our case the effect indicates teachers are less likely to leave high poverty schools after conditioning on other characteristics. The t-statistic associated with the test score variable is 2.69 in their work and 1.62 in our Table 4.

${ }^{20}$ An alternative would be to specify a continuous time competing risks model and to compute likelihood contributions on the basis of the interval in which a person left his/her first teaching job. This is the approach taken
} 
The model is estimated by maximum likelihood. Define $P_{i t}^{j}$ to be the probability that at the end of his/her $t^{\text {th }}$ year in teaching, teacher $i$ chooses activity $j, j=F, W, D, E, N, O$, for time $t+1$. There are two cases to consider. First, suppose a person's spell in teaching at his/her first job is censored after $S$ years in teaching. In this case, the likelihood contribution for teacher $i$ is the probability that at the end of years $1,2, \ldots, S-1$, the person decides to return to teaching at the first school for the next year:

$$
L_{i}=P_{i 1}^{F} \bullet P_{i 2}^{F} \bullet \ldots \bullet P_{i S-1}^{F} \text {. }
$$

The likelihood contribution is similar in the alternative case where the person is not censored. Suppose a person teaches for S years in his first teaching job and then leaves teaching at the first school for option $k \in\{W, D, E, N, O\}$. In this case, the likelihood contribution for the person is the joint probability that at the end of years $1,2, \ldots, S-1$, the person decides to return to teaching for the next year and decides at the end of year $S$ to have activity state $k$ in time $S+1$ :

$$
L_{i}=P_{i 1}^{F} \bullet P_{i 2}^{F} \bullet \ldots \bullet P_{i S-1}^{F} \cdot \bullet P_{i S}^{k}
$$

We define $P_{i t}^{j}$ to have a multinomial logit form:

$$
P_{i t}^{j}=\frac{e^{X_{i t} \beta^{j}+B^{j}(t)}}{e^{X_{i t} \beta^{F}+B^{F}(t)}+e^{X_{i t} \beta^{W}+B^{W}(t)}+e^{X_{i t} \beta^{D}+B^{D}(t)}+e^{X_{i t} \beta^{E}+B^{E}(t)}+e^{X_{i t} \beta^{N}+B^{N}(t)}+e^{X_{i t} \beta^{O}+B^{O}(t)}}
$$

where $X_{i t}$ is the vector of observable personal and school characteristics of teacher $i$ at time $t$ and are described in Table 1. $B^{j}(t)$ is a function which is used to determine how the probability of choosing a particular option $j$ changes with the number of years, $t$, that a person has been in her teaching spell. We assume the same non-parametric form that we used in the linear probability model:

$$
B^{j}(t)=\delta^{j}{ }_{1} I(t=1)+\delta^{j}{ }_{2} I(t=2)+\delta^{j}{ }_{3} I(t=3)+\ldots+\delta^{j}{ }_{6} I(t=6) \text {. }
$$


The likelihood function for the sample is given by $\prod_{i} L_{i} \cdot{ }^{21}$ The coefficient vector $\beta^{F}$ and the coefficients in $\beta^{F}(t)$ are normalized to zero so that the remaining coefficient vectors $\beta^{j}$, $j=W, D, E, N, O$ and the parameters of $\beta^{j}(t), j=W, D, E, N, O$ are the effects relative to the option of remaining in the first teaching job.

The estimation results from the competing risks model are shown in Table 5 . There is a small amount of evidence in Table 5 that wages impact teacher exits from their first teaching job. In particular, we find no evidence of a relationship between teaching wages and exits to occupations outside of the public education sector or exits out of the Georgia workforce and generally only weak evidence of a relationship between teaching wages and other types of exits. ${ }^{22}$

While wages are the characteristic that has been most often studied in the past, what is by far the most striking in Table 5 is the effect of student racial composition. A motivation for employing the competing risks model is that it allows us to examine whether the strong relationship between PBLACK and teacher exits that is observed in the linear probability model is driven primarily by substantial increases in the exit probabilities associated with a small number of the exit activities. While there are some differences in statistical significance by exit activity, the results strongly suggest that this is not the case. Relative to remaining in the same school, teachers in schools with higher proportions of black students (PBLACK) are significantly more likely to change teaching jobs within the same district, to change teaching jobs by moving to new districts, to leave teaching for non-education jobs, and to leave the Georgia workforce altogether. The t-statistics associated with these effects are 3.15, 9.31, 6.49, and 10.72 respectively. ${ }^{23}$ The interaction of PBLACK with the

\footnotetext{
${ }^{21}$ In this specification, conditional on the observable characteristics, the year specific likelihood contributions are independent.

${ }^{22}$ There is a negative and statistically significant relationship between teaching wages and exits to other education jobs (t-statistic of -4.56). However, as shown in Table 2, relatively few teachers (7.3 percent) make this transition. In addition, tests of the null hypotheses that teaching wages have no effect on exits to new schools in the same district and exits to new schools in new districts respectively can be rejected, but only at significance levels greater than approximately .11.

${ }^{23}$ There are a variety of ways that policymakers may find the competing risks analysis, which disaggregates the single exit category used in the linear probability model, to be useful. For example, if it had been observed that
} 
indicator of whether a teacher is black (BLACK) indicates that black teachers are significantly less likely to leave minority schools than are white teachers.

Table 5 also reveals that POVERTY has an insignificant effect on transitions to both types of new teaching jobs and that the TEST variable has estimated effect t-statistics of -1.51 and -1.81 in the equations related to movements to a new school in the same district and a new school in a new district respectively. ${ }^{24}$ Thus, the results suggest that the univariate relationships between teacher job changes and the POVERTY and TEST variables that were found in Section III.1 are to a large extent driven by their correlation with the other school characteristics in the model, most notably the racial makeup of schools. As in the linear probability model, we confirmed this using two additional specifications. In one alternative specification we excluded the TEST and PBLACK variables and found that the estimated coefficient on POVERTY was 1.201 (t-statistic of 11.04) in the change districts transition and 0.353 (t-statistic of 4.14) in the new school/same district transition. In a second alternative specification we excluded the POVERTY and PBLACK variables and found that the estimated coefficient on TEST was -0.017 (t-statistic of -8.97) in the change districts transition and -0.004 (t-statistic of -3.07) in the new school/same district transition.

In order to quantify the importance of the various school characteristics, we use our estimates in Table 5 to compute the first-year exit probability associated with each of the exit reasons for a

PBLACK was related to only exits out of teaching altogether, one possible interpretation would have been that an initial teaching assignment in a particular type of school tends to influence how teachers view teaching more generally. However, the fact that many teachers who start in schools with large proportions of black students change schools rather than exiting teaching altogether suggests that this is not necessarily the case. Indeed, the fact that teachers in these schools have opportunities to move to other types of schools raises the possibility that many teachers may know in advance that their stays in these types of schools may be relatively short. That is, it is possible that a teacher may initially accept a job in particular type of school just to "get her foot in the door." While understanding the process by which people decide whether to initially enter teaching (or whether to accept certain types of initial teaching jobs) is an important research topic, our data is not well-suited for examining this issue. ${ }^{24}$ POVERTY is found to have a positive effect on transitions to other education sector jobs (t-statistic of 2.21), and, curiously we find a negative and statistically significant effect of POVERTY on transitions to non-education sector jobs and out of the Georgia workforce. This result is consistent with the findings in Hanushek et al. (2004) and Clotfelter et al. (2002). Both studies find that the percent of students in poverty has a negative effect on exits from teaching. In earlier work, Scafidi, et al. (2002) find that adding measures of local labor market conditions (county and region unemployment rate and earnings, and region dummy variables) as explanatory variables does not have 
"baseline” person at a "baseline school” and then compare these probabilities to those obtained after changing the values of the school characteristics one at a time. ${ }^{25}$ As shown in Table 6 , for the baseline person the sum of the first-year exit probabilities associated with the five possible transition risks is 29.7 percent. Increasing wages by one standard deviation $(\$ 4,674)$ decreases the predicted probability of leaving the first job in the first year by only one percentage point. Increasing test scores at the baseline school by one standard deviation (14.69 points) decreases the probability of leaving the first job in the first year by only one-half of one percentage point. Increasing the school's poverty rate by one standard deviation (0.27) decreases the probability of leaving the current school by about eight-tenths of a percentage point. Thus, although there are statistically significant impacts of student test scores, poverty rates, and wages on a small number of teacher transitions, the overall impacts of these school characteristics on teacher mobility and retention are quite small. By contrast, increasing the proportion of black students by one standard deviation (0.32) increases the probability of leaving the first job in the first year by 6.5 percentage points. This 22 percent increase is consistent with what was found using the linear probability model.

\section{III.3 Changes in School Characteristics Associated with Changing Schools}

The analyses in the previous section suggest that teachers who serve higher proportions of minority students are more likely to leave their first teaching job - by moving to new schools within their districts, by moving to new districts, and by taking jobs outside of the public education sector. Although this analysis utilizes only the school characteristics in a teacher's first teaching job, it suggests that we should perhaps expect that the schools to which teachers move will be substantially different than the schools that they leave. In this section, we examine this issue by computing the

much of an impact on the magnitude or significance of the impact of wages or school characteristics on teacher transitions.

${ }^{25}$ The baseline person is a non-black female teacher with all other explanatory variables set to the sample means. 
changes in wages and school characteristics that are experienced by teachers who move to new schools. These results are displayed separately in Table 7 for teachers who change schools within the same district (column 1) and teachers who change districts (column 2).

Given annual changes in salary, our data indicate that teachers who remained in their first teaching jobs received an annual wage increase of approximately $\$ 1,820$ during the sample period. Thus, Table 7 shows that the wage increases experienced by teachers who changed teaching jobs are not substantially higher (less than 1 percent) than the increases experienced by teachers who did not change jobs. However, consistent with what we might expect given our previous findings, Table 7 indicates that teachers who changed schools did experience changes in non-pecuniary school characteristics. Teachers who moved to new schools within their first school district experienced an average increase in TEST of 3.37 points and average decreases in POVERTY and PBLACK of 5.4 and 3.9 percentage points, respectively. ${ }^{26}$ Teachers who moved to new schools in different districts experienced an average increase in TEST of 8.0 points and average decreases in POVERTY and PBLACK of 11.7 and 13.3 percentage points, respectively.

The changes in school characteristics for movers in the present study are consistent with the univariate analysis in Lankford, et al. (2002), which reports that New York State teachers tend to move away from disadvantaged students in a similar fashion. These changes for movers are also broadly consistent with evidence from the California class size reduction that began in the mid 1990s. The sudden and large decrease in class sizes mandated by the state of California created new teacher positions in virtually every school in the state. As reported in Reichardt (2000) and Betts, et al. (2000), incumbent teachers who served lower achieving, minority, and low-income students were more likely to transfer to schools that had less of these types of students.

\footnotetext{
${ }^{26}$ Test scores are recorded only for teachers who move to another elementary school. A handful moved to middle or high schools.
} 


\section{Conclusion}

The main contribution of this paper is to provide new information about the types of schools where turnover is the highest. We find strong evidence that students with large percentages of black students have much higher attrition rates than other types of schools. While there are many reasons to think that such results would vary to some extent based on the demographic nature and educational systems of different states, the message from our work is remarkably similar to that of Hanusek et al. (2004) who study teachers in the state of Texas. 
There are many reasons that policymakers may find it useful to have a better understanding of the attrition rates at various types of schools. Prominent among these is a concern that, if attrition is concentrated at particular types of schools, then certain types of students may systematically receive a lower quality education than other students. On one hand, suppose that teachers receive less enjoyment in minority schools for reasons unrelated to teaching effectiveness. In this case, teachers of all quality will want to leave these schools and it will likely be the better teachers who will be able to find new principals who agree to hire them. Thus, under the seemingly reasonable assumption that minority schools do not get better new hires than other schools, it seems likely that high attrition rates at black schools will tend to be indicative of lower quality education in this case. However, conclusions tend to be more ambiguous if some subset of teachers find teaching less enjoyable because they are less effective teaching in minority schools and the high attrition rates result from these teachers finding better school matches. In this case, it will be the teachers who are more effective in minority schools who will remain and minority schools may only be worse than other schools to the extent that it takes the less effective teachers time to leave these schools or to the extent that there are not enough teachers who are effective at teaching in minority schools to fill all of the positions at these schools. ${ }^{27}$

At first glance, the discussion in the paper might suggest that it is quite plausible to believe that some subset of teachers are less effective teaching in black schools; one might think that black schools like other high poverty schools may be challenging places to teach effectively and teacher

\footnotetext{
${ }^{27}$ For simplicity, this discussion focuses on teachers who are changing schools. At an intuitive level, one might think that teachers who leave first teaching jobs for other teaching jobs may be of higher quality than those who leave first teaching jobs for other exit activities such as taking care of young children. One reason that one might expect this is that, in order to change teaching jobs, one typically has to find a principal who is willing to accept the teacher while this type of review is not needed to leave the workforce altogether. In this case, knowing whether or not the high rate of exits from minority schools is generated primarily by exits to particular types of activities may provide information that is useful for thinking about potential quality implications of turnover at these schools. Our competing risks model finds that the proportion of students that are black has strong relationships to virtually all of the exit reasons.
} 
characteristics such as energy, motivation, and patience, which are presumably valuable in these types of schools, may be possessed by only a subset of teachers. However, if race per se does not make a particular student more difficult to teach, our empirical finding that high attrition rates do not appear in high poverty, low test score, non-minority schools casts a serious doubt on the plausibility of believing that the force driving mobility in minority schools is differences in teaching effectiveness generated by general characteristics such as motivation, energy, and patience. In particular, it would have to be the case that (1) the TEST and POVERTY variables do not fully measure the factors that determine how challenging it is to teach effectively in a particular school and (2) the portion not captured by these variables is both spuriously being attributed to the PBLACK variable in our empirical work and happens to be the portion that requires general teacher attributes such as energy, motivation, and patience. If these conditions are not satisfied, one needs explanations in which some subset of teachers are more effective teaching black students for reasons directly related to race. One obvious possibility is that black teachers are more effective at teaching black students than non-black teachers. ${ }^{28}$ However, as discussed in detail earlier in this section, while this explanation may imply that minority schools tend to replace departing teachers with teachers who on average are more effective, it suggests that minority schools will be of lower quality if there does not exist enough black teachers to staff all black schools.

We note that the specifications in the paper undoubtedly suffer from omitted school variables that are potentially correlated with our PBLACK variable. As a result, it is important to note that even if attrition is caused by preferences that are unrelated to teaching effectiveness, it is very possible that teachers find teaching in black schools to be less enjoyable for reasons unrelated to

\footnotetext{
${ }^{28}$ There is a large literature focused on how the race and gender of faculty relate to students of different race and gender. Generally, the focus of this research has been on such issues as the attitudes towards and expectations of students, but not student performance; this research is discussed by Ehrenberg and Brewer (1995). We identified one paper that addressed the relationship between the race of a teacher and the performance of students. Using the National Educational Longitudinal Study of 1988, Ehrenberg, Goldhaber and Brewer (1995) find that "for the most part [the race, gender and ethnicity of the teacher] did not affect how much students learned.”
} 
simple racial bias. However, given that black teachers are not more likely to leave black schools than white schools, omitted school variables of relevance must influence white teachers differently than black teachers. The type of possibility that would be relevant is that white teachers may tend to live further from black schools than black teachers.

The discussion suggests that future research that provides direct evidence about the relationship between teacher turnover and teacher quality would be very valuable. 


\section{References}

Betts, J.R., K.S. Reuben, and A. Danenberg (2000). Equal Resources, Equal Outcomes? The Distribution of School Resources and Student Achievement in California. San Francisco CA: Public Policy Institute of California.

Clotfelter, C.T. (1999). "Public School Segregation in Metropolitan Areas.” Land Economics 25 (November): 487-504.

Clotfelter, C.T., H.F. Ladd, and J.L. Vigdor (2003). "Who Teachers Whom? Race and the Distribution of Novice Teachers.” Duke University working paper.

Dolton, P. and W. van der Klaauw (1999). “The Turnover of Teachers: A Competing Risks Explanation.” Review of Economics and Statistics 81(3): 543-52.

Ehrenberg, Richard G., Daniel D. Goldhaber, and Domminic J. Brewer (1995). “Do Teachers’ Race, Gender, and Ethnicity Matter? Evidence From the National Educational Longitudinal Study of 1988." Industrial and Labor Relations Review 48(2): 547-61.

Ehrenberg, Richard G. and Domminic J. Brewer (1995). “Did Teachers’ Verbal Ability and Race Matter in the 1960s? Coleman Revisited.” Economics of Education Review 14(1): 1-21.

Freeman, C., B. Scafidi, and D.L. Sjoquist (2002). "Racial Segregation in Georgia Public Schools, 19942001: Trends, Causes, and Impact on Teacher Quality.” Georgia State University working paper.

Ferguson, Ronald F. (1991). "Paying for Public Education: New Evidence of How and Why Money Matters.” Harvard Journal on Legislation 28(summer): 465-98.

Ferguson, Ronald F. and Helen F. Ladd (1996). "How and Why Money Matters: An Analysis of Alabama Schools.” In Holding Schools Accountable: Performance Based Reform in Education, Helen F. Ladd (ed.). Washington, DC: Brookings Institution Press, pp. 265-99.

Georgia Department of Education (2002). "School Report Cards.” Available at: http://accountability. doe.k12.ga.us/report01.

Gritz, M.R., and N.D. Theobald (1996). "The Effects of School District Spending Priorities on Length of Stay in Teaching.” Journal of Human Resources 31(summer): 477-512.

Hanushek, E.A, J.F. Kain, and S.G. Rivkin (2004). "Why Public Schools Lose Teachers.” Journal of Human Resources 39(2): 326-54.

Lankford, H., S. Loeb, and J. Wyckoff (2002). "Teacher Sorting and the Plight of Urban Schools: A Descriptive Analysis.” Education Evaluation and Policy Analysis 24(1): 37-62.

Mont, D. and D.I. Rees (1996). “The Influence of Classroom Characteristics on High School Teacher Turnover.” Economic Inquiry 34(1): 152-67.

Murnane, R. and R. Olsen (1990). "The Effects of Salaries and Opportunity Costs on Duration in Teaching: Evidence from North Carolina.” Journal of Human Resources 25(1): 106-24. 
Reichardt, Robert (2000). “The Movement of Teachers During the First Year of CSR in California.” MidContinent Research for Education and Learning working paper, Aurora, CO.

Rivkin, S., E. Hanushek, and J. Kain (1998). “Teachers, Schools and Academic Achievement.” National Bureau of Economic Research Paper 6691.

Salzer, J. (2001). "State Teachers Top Wage Scale: Georgia Salaries $1^{\text {st }}$ in Southeast, $17^{\text {th }}$ Nationwide.” Atlanta Journal-Constitution (May 17).

Sanders, William L. and Sandra P. Horn (1998). "Research Findings from the Tennessee Value-Added Assessment System (TVAAS) Data Base: Implications for Educational Evaluation and Research.” Journal of Personnel Evaluation in Education 12(3): 247-56.

Sanders, William L., A. M. Saxton, and Sandra P. Horn (1997). "The Tennessee Value-Added Assessment System (TVAAS): A Quantitative, Outcomes-Based Approach to Educational Assessment.” In Grading Teachers, Grading Schools, J. Millman (ed.). Thousand Oaks, CA: Corwin Press.

Scafidi, B., D.L. Sjoquist, and T.R. Stinebrickner (2002). “Where Do Teachers Go?” Georgia State University working paper.

Stinebrickner, Todd R. (2001). “Compensation Policies and Teacher Decisions.” International Economic Review 42(3): 751-89.

Stinebrickner, Todd R. (2002). "An Analysis of Occupational Change and Departures from the Labor Force; Evidence of the Reasons that Teacher Quit.” Journal of Human Resources 37(1): 192-216.

Theobald, N.D. (1990). “An Examination of the Influence of Personal, Professional, and School District Characteristics on Public School Teacher Retention.” Economics of Education Review 9(3):24150.

Theobald, N.D. and R. M. Gritz (1996). "The Effect of School District Spending Priorities on the Exit Paths of Beginning Teachers Leaving the District.” Economics of Education Review 15(1):11-22.

White, S. and L. Geddes (1990). "ES202: The Database for Local Employment Analysis.” Economic Development Quarterly 4(August): 240-53. 
TABLE 1: SUMMARY STATISTICS - FIRST YEAR OF TEACHING SPELL

\begin{tabular}{lcc}
\hline Variable & Mean & Std. Dev. \\
\hline WAGE & 29783 & 4674 \\
LOGWAGE - Log(Wage) & 10.35 & 0.155 \\
TEST - Test score students* & 53.28 & 14.69 \\
POVERTY - Proportion of students in poverty** & 0.464 & 0.273 \\
PBLACK - Proportion of black students & 0.388 & 0.319 \\
MALE - Teacher is male & 0.125 & 0.33 \\
BLACK - Teacher is black & 0.167 & 0.373 \\
BLACK*PBLACK & 0.112 & 0.281 \\
\hline
\end{tabular}

$\mathrm{N}=11,070$

*Student test score equals the average 3rd grade percentile rank on the Iowa Test of Basic Skills Exam (ITBS Math + ITBS Reading)/2.

**POVERTY is the proportion of children in school eligible for free or reduced price lunch.

TABLE 2: TEACHER TRANSITIONS

\begin{tabular}{lcc}
\hline Transition Category & Number of Teachers & Percent of Teachers \\
\hline Same School* & 4222 & $38.1 \%$ \\
New School / Same District & 2319 & $20.9 \%$ \\
New District & 1374 & $12.4 \%$ \\
Other Education Sector Job & 803 & $7.3 \%$ \\
Non-Education Sector job** & 343 & $3.1 \%$ \\
Out of GA Workforce & 2009 & $18.1 \%$ \\
Total & 11070 & $100.0 \%$ \\
\hline
\end{tabular}

*Teachers who remained at the same school the entire sample period.

**Former teachers who earned less than $\$ 10,000$ in a non-education sector job were classified as out of the GA workforce.

TABLE 3: SCHOOL CHARACTERISTICS IN PRIOR YEAR BY TRANSITION CATEGORY

\begin{tabular}{|c|c|c|c|c|c|c|c|}
\hline & $\begin{array}{c}\text { (1) } \\
\text { Same } \\
\text { School }\end{array}$ & $\begin{array}{c}(2) \\
\text { New School/ } \\
\text { Same } \\
\text { District } \\
\end{array}$ & $\begin{array}{c}(3) \\
\text { New } \\
\text { District }\end{array}$ & $\begin{array}{c}(4) \\
\text { Other Educ } \\
\text { Sector Job }\end{array}$ & $\begin{array}{c}\text { (5) } \\
\text { Non-Educ } \\
\text { Sector Job }\end{array}$ & $\begin{array}{c}\text { (6) } \\
\text { Out of GA } \\
\text { Workforce }\end{array}$ & $\begin{array}{c}\text { (7) } \\
\text { Exit for } \\
\text { Any Reason } \\
\text { (2)-(6) }\end{array}$ \\
\hline WAGE & 31711 & 31595 & $31,422 *$ & $30,617 * * *$ & 31704 & 31833 & $31,549 * * *$ \\
\hline TEST & 54.47 & $53.25 * * *$ & $51.00 * * *$ & $53.00 * * *$ & $52.47 *$ & 54.17 & $53.01 * * *$ \\
\hline POVERTY & 0.461 & $0.481^{* *}$ & $0.535^{* * *}$ & $0.501^{* * *}$ & 0.436 & 0.458 & $.485^{* * *}$ \\
\hline PBLACK & 0.372 & $0.393 * *$ & $0.466 * * *$ & $0.397 *$ & $0.427 * * *$ & $0.406 * * *$ & $.414 * * *$ \\
\hline
\end{tabular}


TABLE 4: LinEAR PROBABILITY MODEL OF TEACHER TRANSITIONS

\begin{tabular}{lccc}
\hline Variable & Coefficient & Std. Error & T-Stat \\
\hline Log Teaching Wage & -0.058 & 0.022 & -2.65 \\
$\delta 1$ & 0.402 & 0.052 & 7.69 \\
$\delta 2$ & 0.374 & 0.053 & 6.97 \\
$\delta 3$ & 0.389 & 0.054 & 7.09 \\
$\delta 4$ & 0.403 & 0.056 & 7.14 \\
$\delta 5$ & 0.395 & 0.058 & 6.77 \\
$\delta 6$ & 0.427 & 0.062 & 6.89 \\
MALE & 0.007 & 0.008 & 0.83 \\
BLACK Teacher & 0.031 & 0.016 & 1.89 \\
TEST Score Students & -0.0003 & 0.0002 & -1.62 \\
POVERTY Students & -0.038 & 0.016 & -2.34 \\
PBLACK Students & 0.188 & 0.015 & 12.47 \\
BLACK x PBLACK & -0.209 & 0.024 & -8.60 \\
\hline
\end{tabular}


TABLE 5: COMPETING RISKS MODEL OF TEACHER TRANSITIONS

\begin{tabular}{|c|c|c|c|c|}
\hline Risk & Variable & Coefficient & Std. Error & T-Stat \\
\hline \multicolumn{5}{|c|}{ New School/Same District } \\
\hline & Log Teaching Wage & -0.274 & 0.172 & -1.60 \\
\hline & $\delta 1$ & -1.383 & 0.411 & -3.37 \\
\hline & $\delta 2$ & -1.485 & 0.422 & -3.52 \\
\hline & $\delta 3$ & -1.468 & 0.432 & -3.40 \\
\hline & $\delta 4$ & -1.29 & 0.444 & -2.90 \\
\hline & $\delta 5$ & -1.217 & 0.458 & -2.66 \\
\hline & $\delta 6$ & -1.143 & 0.484 & -2.36 \\
\hline & MALE & 0.116 & 0.066 & 1.75 \\
\hline & BLACK Teacher & 0.124 & 0.134 & 0.92 \\
\hline & TEST Score Students & 0.003 & 0.002 & -1.51 \\
\hline & POVERTY Students & 0.057 & 0.131 & 0.43 \\
\hline & PBLACK Students & 0.373 & 0.118 & 3.15 \\
\hline & BLACK x PBLACK & -0.611 & 0.196 & -3.12 \\
\hline \multicolumn{5}{|c|}{ New District } \\
\hline & Log Teaching Wage & -0.361 & 0.219 & -1.65 \\
\hline & $\delta 1$ & -2.105 & 0.524 & -4.02 \\
\hline & $\delta 2$ & -2.034 & 0.538 & -3.78 \\
\hline & $\delta 3$ & -1.874 & 0.549 & -3.41 \\
\hline & $\delta 4$ & -2.103 & 0.566 & -3.71 \\
\hline & $\delta 5$ & -2.031 & 0.586 & -3.47 \\
\hline & $\delta 6$ & -1.856 & 0.62 & -3.00 \\
\hline & MALE & 0.0004 & 0.09 & 0.005 \\
\hline & BLACK Teacher & 0.661 & 0.172 & 3.85 \\
\hline & TEST Score Students & -0.005 & 0.002 & -1.81 \\
\hline & POVERTY Students & 0.212 & 0.166 & 1.27 \\
\hline & PBLACK Students & 1.325 & 0.142 & 9.31 \\
\hline & BLACK x PBLACK & -2.122 & 0.255 & -8.32 \\
\hline \multicolumn{5}{|c|}{ Other Education Sector Job } \\
\hline & Log Teaching Wage & -1.322 & 0.29 & -4.56 \\
\hline & $\delta 1$ & -0.177 & 0.685 & -0.26 \\
\hline & $\delta 2$ & -0.79 & 0.706 & -1.12 \\
\hline & $\delta 3$ & -0.842 & 0.724 & -1.16 \\
\hline & $\delta 4$ & -0.523 & 0.744 & -0.70 \\
\hline & $\delta 5$ & -0.32 & 0.768 & -0.42 \\
\hline & $\delta 6$ & 0.241 & 0.799 & 0.30 \\
\hline
\end{tabular}

Table 5 continues next page... 
TABLE 5 (CONTINUED): COMPETING RISKS MODEL OF TEACHER TRANSITIONS

\begin{tabular}{|c|c|c|c|c|}
\hline Risk & Variable & Coefficient & Std. Error & T-Stat \\
\hline \multicolumn{5}{|c|}{$\begin{array}{l}\text { Other Education Sector Job } \\
\text { (continued) }\end{array}$} \\
\hline & BLACK Teacher & -0.112 & 0.232 & -0.48 \\
\hline & TEST Score Students & 0.002 & 0.003 & 0.56 \\
\hline & POVERTY Students & 0.481 & 0.217 & 2.21 \\
\hline & PBLACK Students & 0.148 & 0.197 & 0.75 \\
\hline & BLACK x PBLACK & -0.004 & 0.33 & -0.01 \\
\hline \multicolumn{5}{|c|}{ Non-Education Sector Job } \\
\hline & Log Teaching Wage & -0.238 & 0.43 & -0.55 \\
\hline & $\delta 1$ & -2.573 & 1.023 & -2.52 \\
\hline & $\delta 2$ & -2.908 & 1.053 & -2.76 \\
\hline & $\delta 3$ & -2.518 & 1.074 & -2.35 \\
\hline & $\delta 4$ & -2.662 & 1.107 & -2.40 \\
\hline & $\delta 5$ & -3.504 & 1.186 & -2.96 \\
\hline & $\delta 6$ & -4.245 & 1.516 & -2.80 \\
\hline & MALE & 0.553 & 0.138 & 4.02 \\
\hline & BLACK Teacher & 0.321 & 0.327 & 0.98 \\
\hline & TEST Score Students & -0.011 & 0.004 & -2.57 \\
\hline & POVERTY Students & -1.882 & 0.326 & -5.78 \\
\hline & PBLACK Students & 1.832 & 0.282 & 6.49 \\
\hline & BLACK x PBLACK & -1.238 & 0.472 & -2.62 \\
\hline \multicolumn{5}{|c|}{ Out of GA Workforce } \\
\hline & Log Teaching Wage & 0.124 & 0.184 & 0.67 \\
\hline & $\delta 1$ & -2.542 & 0.442 & -5.75 \\
\hline & $\delta 2$ & -2.658 & 0.454 & -5.86 \\
\hline & $\delta 3$ & -2.592 & 0.464 & -5.59 \\
\hline & $\delta 4$ & -2.467 & 0.476 & -5.18 \\
\hline & $\delta 5$ & -2.751 & 0.495 & -5.55 \\
\hline & $\delta 6$ & -2.611 & 0.526 & -4.96 \\
\hline & MALE & -0.188 & 0.078 & -2.42 \\
\hline & BLACK Teacher & -0.056 & 0.159 & -0.36 \\
\hline & TEST Score Students & 0.001 & 0.002 & 0.41 \\
\hline & POVERTY Students & -0.719 & 0.142 & -5.06 \\
\hline & PBLACK Students & 1.318 & 0.123 & 10.72 \\
\hline & BLACK x PBLACK & -1.173 & 0.228 & -5.14 \\
\hline
\end{tabular}

$\mathrm{N}=11,070$ 
TABLE 6: EFFECT OF WAGES AND SCHOOL CHARACTERISTICS ON LEAVING CURRENT SCHOOL

\begin{tabular}{lcccc}
\hline \multicolumn{5}{c}{ Probability of Leaving Current School } \\
\hline Baseline** & WAGE & TEST & POVERTY & PBLACK \\
\hline $29.74 \%$ & $28.86 \%$ & $29.22 \%$ & $28.91 \%$ & $36.25 \%$ \\
\hline
\end{tabular}

*Table shows the probability of leaving first teaching job after the first year for any reason. The first column shows the probability for a baseline person. The 2nd-5th columns show probabilities when WAGE, TEST, POVERTY, and PBLACK are increased by one standard deviation respectively.

** Baseline probabilities are computed from the estimates of the competing risks model

for a non-black female teacher with all other variables set to their sample means.

TABLE 7: CHANGES IN WAGES AND SCHOOL CHARACTERISTICS OF MOVERS

(1)

New School/

Same District

\begin{tabular}{lcc}
\hline & $\begin{array}{c}(\mathbf{1}) \\
\text { New School/ } \\
\text { Same District }\end{array}$ & $\begin{array}{c}\text { (2) } \\
\text { New District }\end{array}$ \\
\hline WAGE & 2.134 & 1916 \\
TEST* & 3.37 & 7.98 \\
POVERTY & -0.054 & -0.117 \\
PBLACK & -0.039 & -0.133 \\
\hline
\end{tabular}

(2)

New District 